$10-2018$

\title{
Responses of Daphnia Magna to Chronic Exposure of Cadmium and Nickel Mixtures
}

\author{
Edgar Pérez \\ Loyola University Chicago \\ Tham C. Hoang \\ Loyola University Chicago, thoang@luc.edu
}

Follow this and additional works at: https://ecommons.luc.edu/ies_facpubs

Part of the Environmental Chemistry Commons, and the Environmental Sciences Commons

\section{Author Manuscript}

This is a pre-publication author manuscript of the final, published article.

\section{Recommended Citation}

Pérez, Edgar and Hoang, Tham C.. Responses of Daphnia Magna to Chronic Exposure of Cadmium and Nickel Mixtures. Chemosphere, 208, : 991-1001, 2018. Retrieved from Loyola eCommons, School of Environmental Sustainability: Faculty Publications and Other Works, http://dx.doi.org/10.1016/ j.chemosphere.2018.06.063

This Article is brought to you for free and open access by the Faculty Publications and Other Works by Department at Loyola eCommons. It has been accepted for inclusion in School of Environmental Sustainability: Faculty Publications and Other Works by an authorized administrator of Loyola eCommons. For more information, please contactecommons@luc.edu. c) () $\odot$

This work is licensed under a Creative Commons Attribution-Noncommercial-No Derivative Works 3.0 License. (C) Elsevier Ltd. 2018 


\section{Responses of Daphnia magna to chronic exposure of cadmium and nickel mixtures}

\section{Edgar Pérez}

Tham

thoang@luc.edu

Institute of Environmental Sustainability, Loyola University Chicago, 1032 W. Sheridan Road, Chicago IL, 60626, USA

*Corresponding author. 6349 N. Kenmore Ave., BVM 314, Chicago, IL 60660, USA.

Handling Editor: Jim Lazorchak

\section{Abstract}

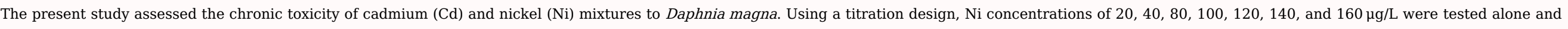

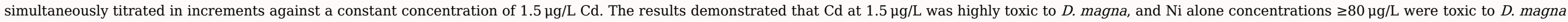

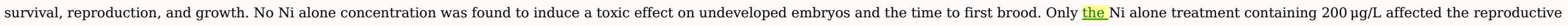
rates of D. magna. For Cd

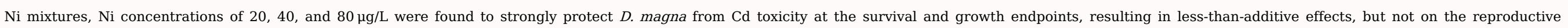

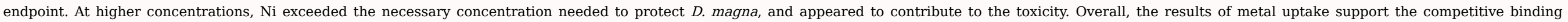
mechanism at the biotic ligand and explain the less-than-additive effects observed in the $\mathrm{Cd}$

Ni mixtures concentration. The embryonic effects of $\mathrm{Cd}$

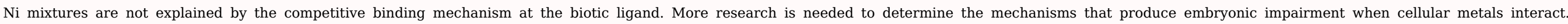
Overall, the results of the present study are relevant for the development of improved environmental quality guidelines for metal mixtures.

Keywords: Daphnia magna; Metal toxicity; Metal uptake; Metal mixture toxicity; Reproductive toxicity; Growth toxicity; Embryonic development

\section{Introduction}

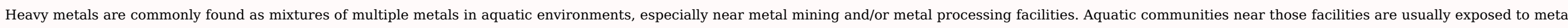

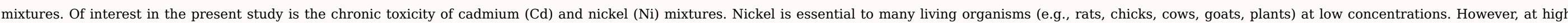

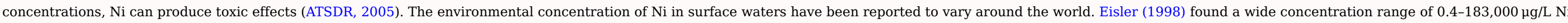
while Balistrieri et al. (2015) found levels ranging from $<1.5$ to $1383 \mu \mathrm{g} / \mathrm{L} \mathrm{Ni} \mathrm{near} \mathrm{Sudbury,} \mathrm{Canada.}$

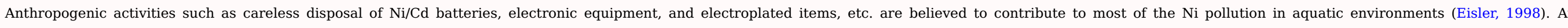

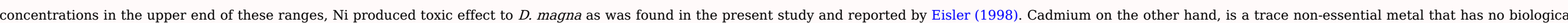

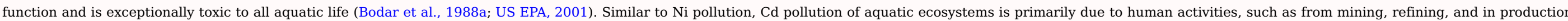

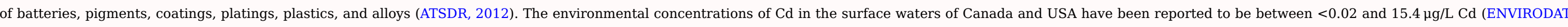
1992; Balistrieri et al., 2015).

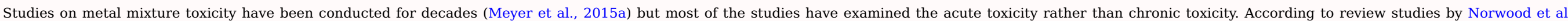




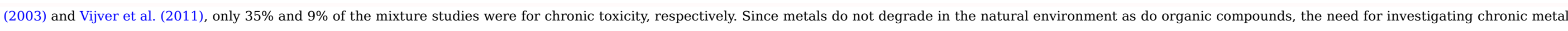

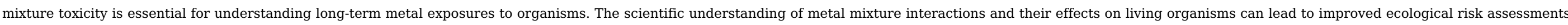
and to the development of water quality guidelines for metal mixtures.

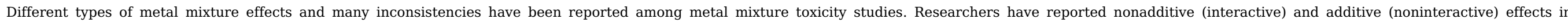

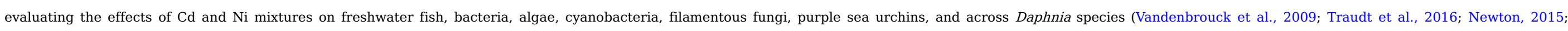

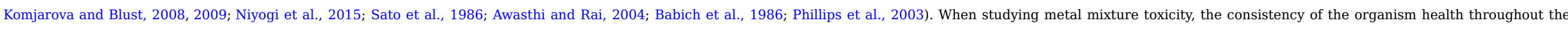

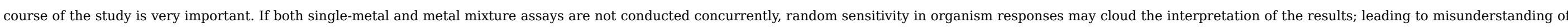

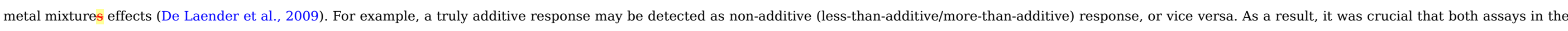
present study (Ni alone and $\mathrm{Cd}$

Ni mixtures) were conducted simultaneously to avoid any misleading toxicity interpretations.

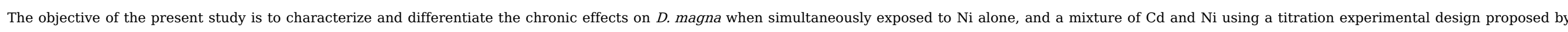
Meyer et al. (2015b), and applied in our earlier study with Cd and Zn mixtures (Pérez and Hoang, 2017). The measured endpoints include: survival, growth, metal accumulation, and reproduction of D. magna.

\section{Materials and methods \\ 2.1 Test organisms}

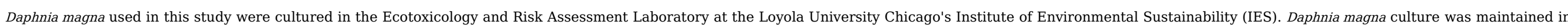

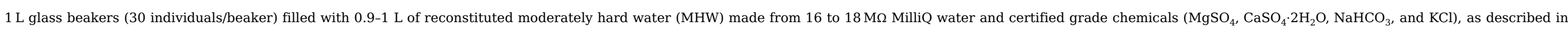
the U.S.EPA chronic toxicity testing method (US EPA, 2002).

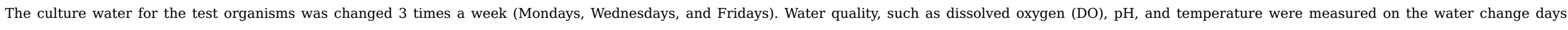

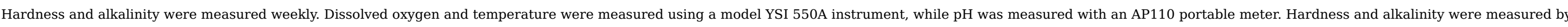

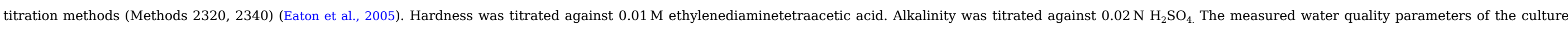

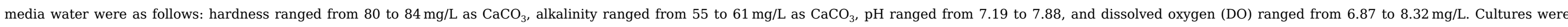
maintained at a temperature ranging from 21.2 to $25.6^{\circ} \mathrm{C}$ and at a light:dark photoperiod of $16 \mathrm{~h}: 8 \mathrm{~h}$.

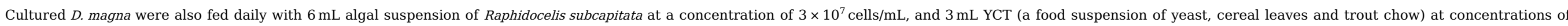

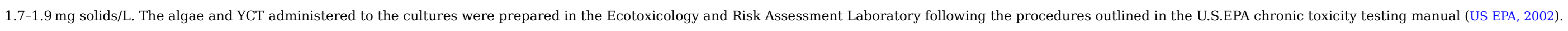

\subsection{Experimental design}

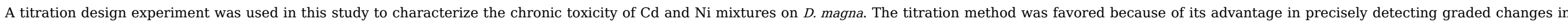
organism responses across a series of increasing metal concentrations (Meyer et al., 2015b). Based on previous Cd and Ni chronic toxicity tests in our laboratory (unpublished data), Cd

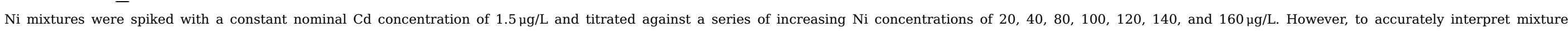
effects, a concurrent control consisting of $\mathrm{MHW}$, a Cd alone treatment containing only $\mathrm{Cd}$, and a $\mathrm{Ni}$ alone test consisting of the same Ni concentration series as those used in the $\mathrm{Cd}$

Ni mixtures were also tested. Overall, the study was comprised of 2 toxicity tests (Ni alone, and $\mathrm{Cd}$

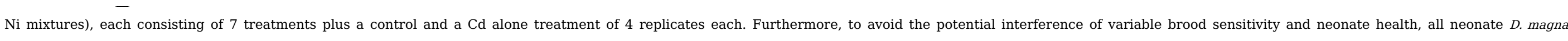
used in the present study were coming from the same brood (5th).

\subsection{Test method and experimental procedures}




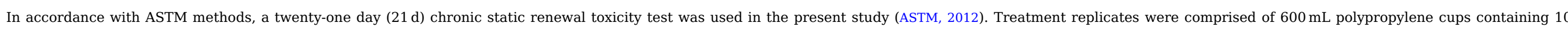

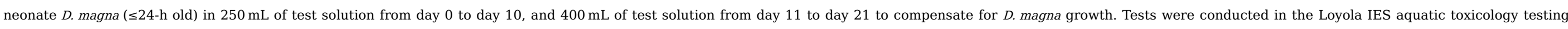

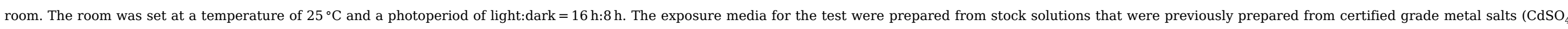
and $\mathrm{ZnCl}_{2}$ ) every 48 -h for renewal.

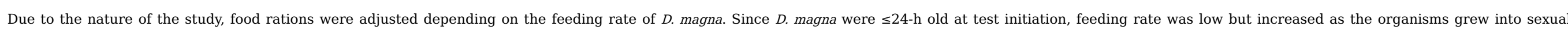

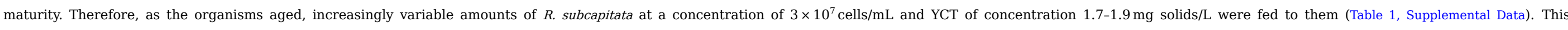
adjustment of the feeding rate also helped reducee the growth of unconsumed algae.

Mortality was recorded daily for both tests (Ni alone and $\mathrm{Cd}$

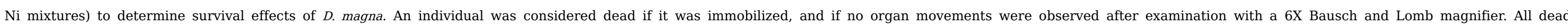
organisms were removed from the test chambers and discarded.

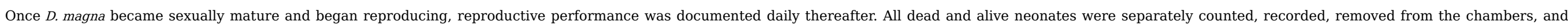

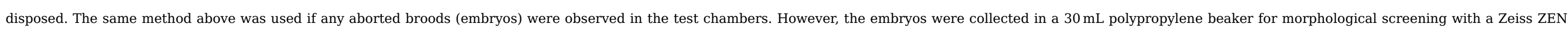

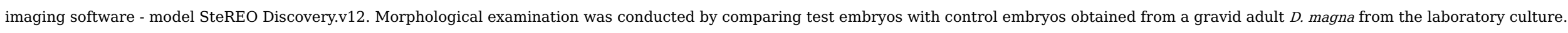

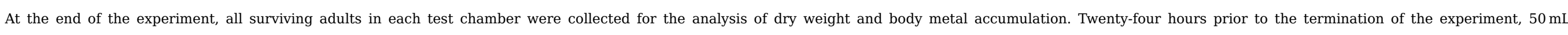

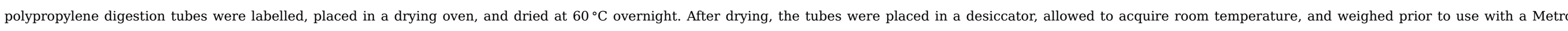

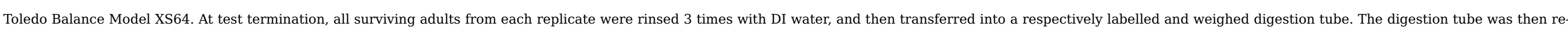

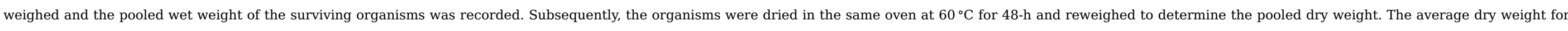

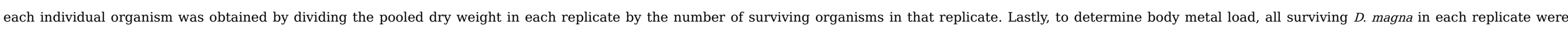
digested with concentrated nitric acid $\left(\mathrm{HNO}_{3}\right)$ as described in the U.S. EPA Method 3050B guidelines (US EPA, 1996). The digested solutions were used for metal analysis.

\subsection{Water quality and chemical analyses}

The physiochemical parameters of the water were measured on days $0,7,14$, and 21 for both toxicity tests ( $\mathrm{Ni}$ alone and $\mathrm{Cd}$

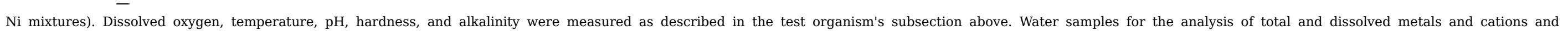
anions $(\mathrm{A} / \mathrm{C})$ were also collected weekly and at the same time that water quality subsamples were taken for water quality measurement.

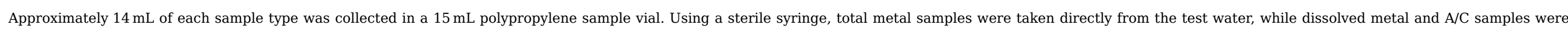

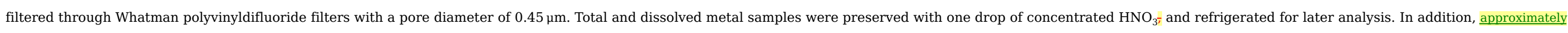
$-25 \mathrm{~mL}$ of sample water was filtered using the same filter type as mentioned above, and collected in a $30 \mathrm{~mL}$ amber glass bottle for later analysis of dissolved organic carbon (DOC).

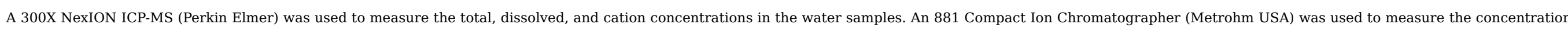
of anions. A TOC-L CSH analyzer (Shimazu) was used to measure the DOC concentrations.

\subsection{Endpoint calculation and data analyses}

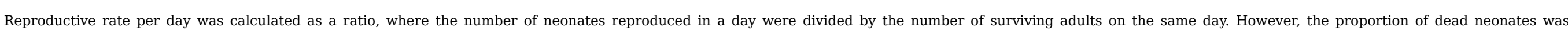

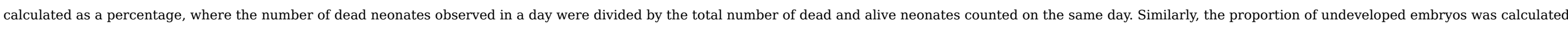
as a percentage of the total number of aborted embryos in a day to the total number of dead and alive neonates + undeveloped embryos counted on the same day.

The data for both the Ni alone test and the $\mathrm{Cd}$ 


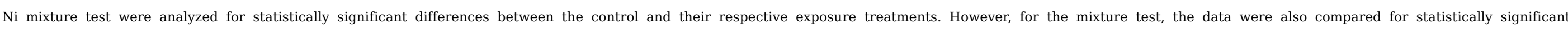
differences between $\mathrm{Cd}$ alone and the $\mathrm{Cd}$

Ni mixtures.

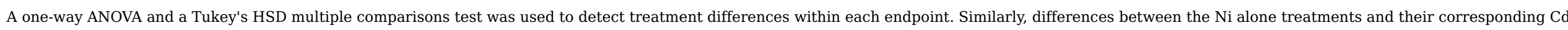
Ni mixtures (e.g., T1 for Ni alone and T1 for Cd

Ni mixture) were also analyzed using the same statistical methods as stated above.

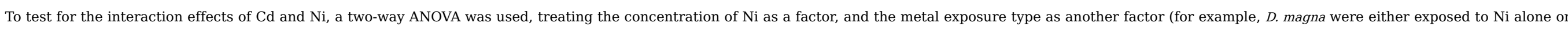
to a corresponding mixture of $\mathrm{Cd}$ and $\mathrm{Ni})$.

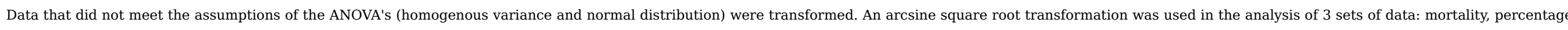

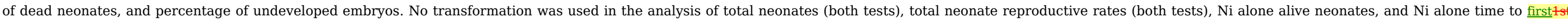

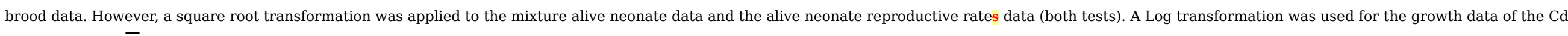
Ni mixtures. The one-way and two-way ANOVAs were conducted with R-Program (Ver 3.1.1).

\section{Results}

\subsection{Water chemistry}

The average measured the and and dissolved $\mathrm{Ni}$ and total $\mathrm{Cd}$ concentrations in both $\mathrm{Ni}$ alone and the $\mathrm{Cd}$

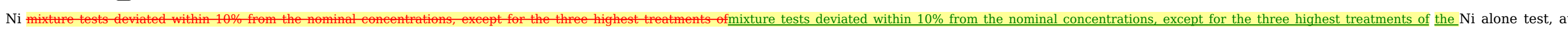

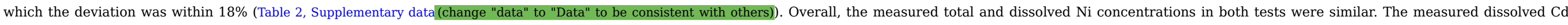

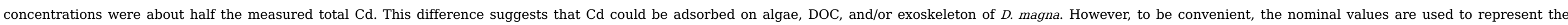
treatment concentrations when the magnitude of the concentrations are not used for effect calculations.

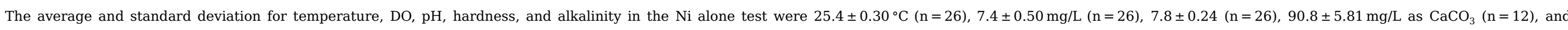
$62.3 \pm 3.93 \mathrm{mg} / \mathrm{L}$ as $\mathrm{CaCO}_{3}(\mathrm{n}=12)$, respectively. For the $\mathrm{Cd}$

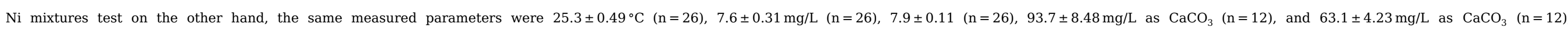
respectively.

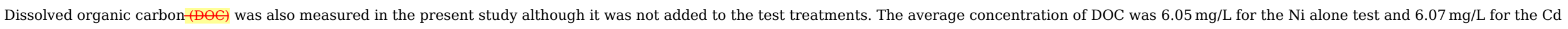
Ni mixture test (Table 3, Supplemental Data). These DOC concentrations were likely coming from the fed diet of D. magna (YCT and algae). Our DOC analysis on the YCT samples confirmed this suspicion.

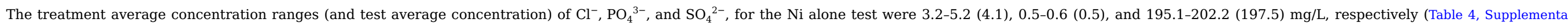
Data). Those same anions in the Cd

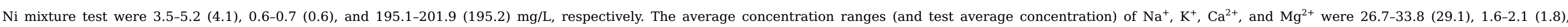
11.5-14.2 (12.5), and 11.1-13.6 (12.1) mg/L for the Ni alone test, and 28.9-36.9 (33.8), 1.8-2.2 (2.0), 12.0-15.4 (14.0), and 11.8-15.2 (13.9) mg/L for Cd

Ni mixture test, respectively (Table 4, Supplemental Data). There was no significant difference in the average concentration of each ion between the two tests.

\subsection{Survival}

In comparison to $\mathrm{Cd}$ alone, the average 21 - $\mathrm{d}$ cumulative mortality percentages were significantly lower in the $\mathrm{Cd}$ 
Ni mixtures containing $20,40,80$, or $100 \mu \mathrm{g} / \mathrm{L} \mathrm{Ni}(p<0.01)$, but not in the other Cd

Ni mixtures (Fig. 1). These results demonstrate that when Ni is present at concentrations $\leq 100 \mu \mathrm{g} / \mathrm{L}$ in a mixture with $1.5 \mu \mathrm{g} / \mathrm{L}$ Cd, mortality substantially decreased, peaking at the Cd

Ni mixture containing $20 \mu \mathrm{g} / \mathrm{L}$ Ni (Fig. 1). The cumulative percent mortality of the Cd

Ni mixture containing $20 \mathrm{\mu g} / \mathrm{L} \mathrm{Ni}(2.5 \%)$ was not significantly different from the control (0\%) (Fig. 1). The low percent mortality of the Cd

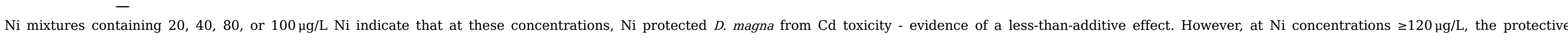

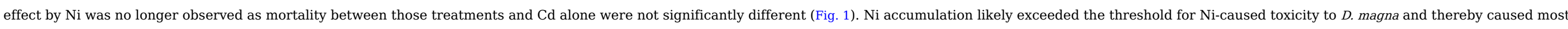
or all of the observed toxicity.

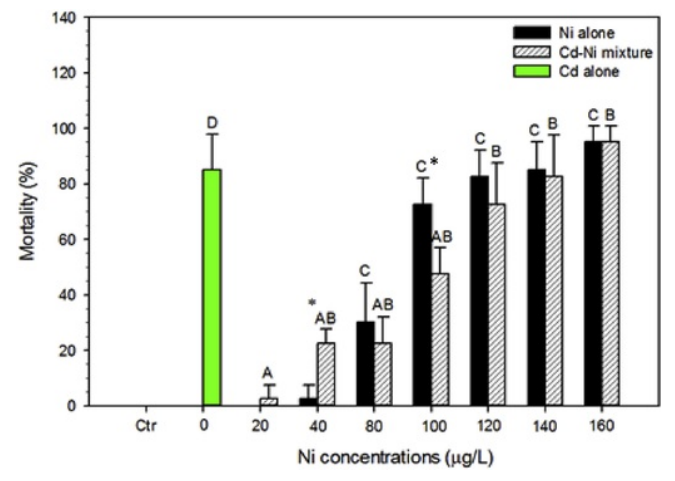

Fig. 1 21-d cumulative mortality of $D$. magna due to exposure to $\mathrm{Cd}$ alone, Ni alone, and Cd므

$\mathrm{Ni}$ mixtures containing constant $\mathrm{Cd}$ concentration of $1.5 \mu \mathrm{g} / \mathrm{L}$ and varied $\mathrm{Ni}$ concentrations. A: significant differences between $\mathrm{Cd}$ alone and $\mathrm{Cd}$

Ni mixtures $(p<0.01)$. B: significant differences between control and Cd

Ni mixtures ( $p<0.01)$. C: significant differences between control and Ni alone $(p<0.001)$. D: significant difference between control and Cd alone $(p<0.001)$. *: significant differences between a Ni alone and its corresponding Cd

Ni mixture $(p<0.05)$. Error bars represent standard deviations.

("Cd-Ni" in the figure title should be one word and in the same line) alt-text: Fig. 1

In comparing the cumulative percent mortality between $\mathrm{Ni}$ alone treatments and their corresponding $\mathrm{Cd}$

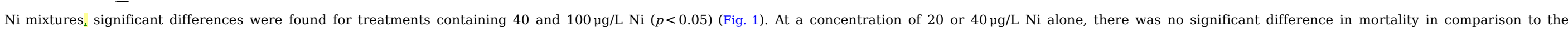
control (Fig. 1). Therefore, the toxicity observed in the $\mathrm{Cd}$

Ni mixture containing $40 \mu \mathrm{g} / \mathrm{L}$ Ni was likely due to Cd exposure. At 80, 120, 140, and $160 \mu \mathrm{g} / \mathrm{L} \mathrm{Ni}$, the mortality of Ni alone and Cd

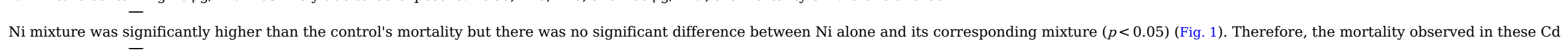

Ni mixtures was mostly due to Ni or both Cd and Ni exposure (Fig. 1).

\subsection{Reproduction}

\subsubsection{Time to first brood, total neonates, live neonates, and reproductive rates}

The average time to first brood in $\mathrm{Cd}$ alone was significantly shorter than the time to first brood in the $\mathrm{Cd}$

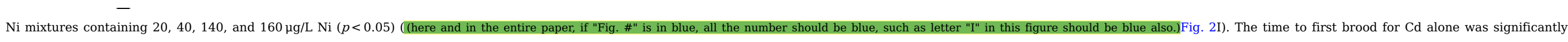




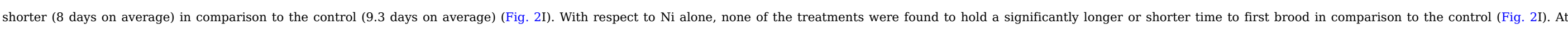

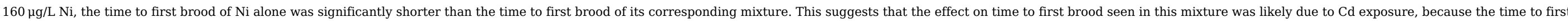
brood in that Ni alone treatment was not significantly different from the control (Fig. 2I).
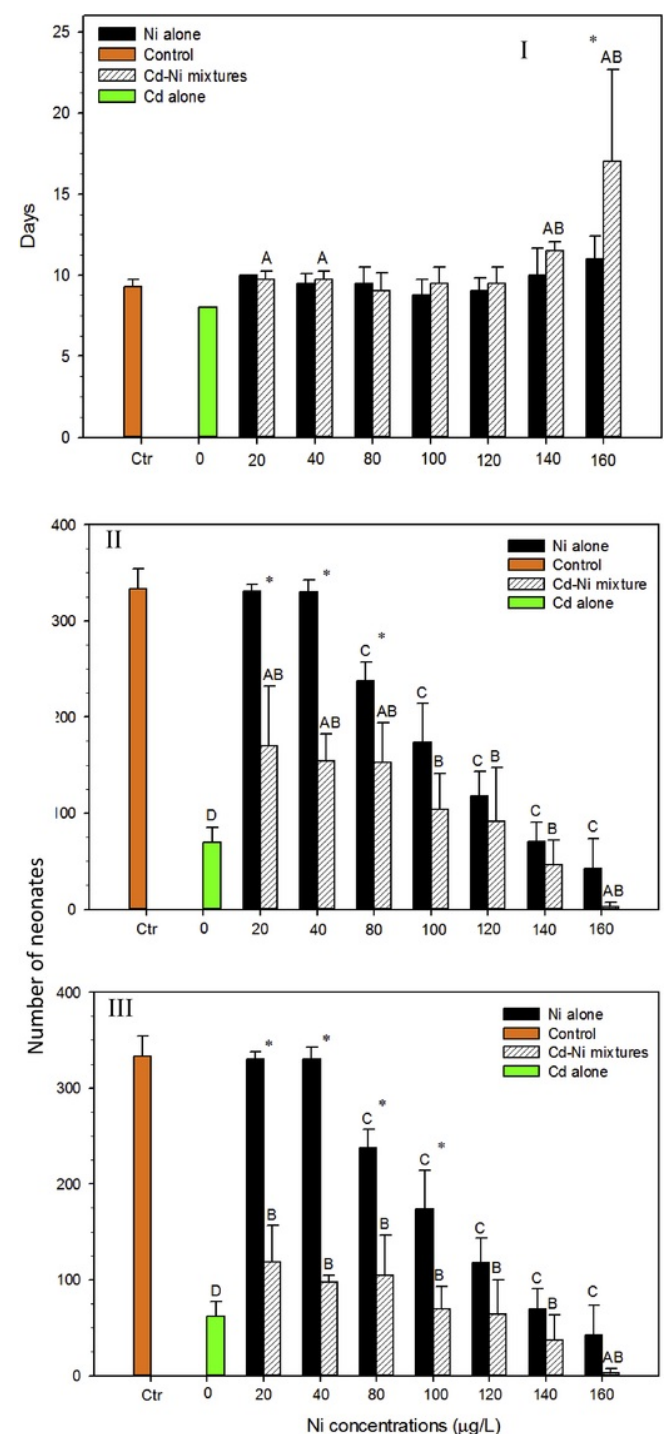

Fig. 2 Time to first brood (I), total dead and live neonates (II) and live neonates (III) reproduced over 21- $\mathrm{d}$ of exposure to Cd alone, Ni alone, and Cd

Ni mixtures containing constant Cd concentration of $1.5 \mu \mathrm{g} / \mathrm{L}$ and varied Ni concentrations. A: significant differences between Cd alone and Cd

Ni mixtures $(p<0.05)$. B: significant differences between control and Cd

Ni mixtures $(p<0.001)$. C: significant differences between control and Ni alone $(p<0.001)$. D: significant difference between control and Cd alone $(p<0.001)$. *: significant differences between a Ni alone and its corresponding Cd 


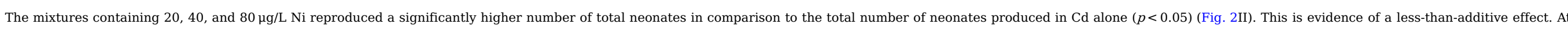
$\mathrm{Ni}$ concentrations of 100,120 , and $140 \mu \mathrm{g} / \mathrm{L}$, there was no significant reproductive effect between $\mathrm{Cd}$

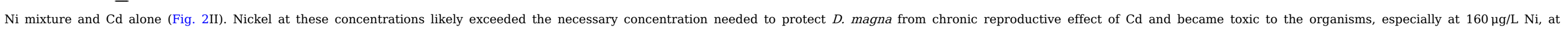
which the number of total neonates in the $\mathrm{Cd}$

Ni mixture was significantly lower than that in Cd alone $(p<0.05)$ (Fig. 2II).

When comparing the total number of neonates between $\mathrm{Ni}$ alone and its corresponding $\mathrm{Cd}$

$\mathrm{Ni}$ mixture, there was a significantly higher number of total neonates in Ni alone compared to $\mathrm{Cd}$

$\mathrm{Ni}$ mixture, there was a significantly higher number of total neonates in Ni alone compared to $\mathrm{Cd}$

$\mathrm{Ni}$ mixture at Ni concentrations of 20,40, and $80 \mu \mathrm{g} / \mathrm{L}$ ( $p<0.05$ ) (Fig. 2II). This signifies that the effect observed in those Cd

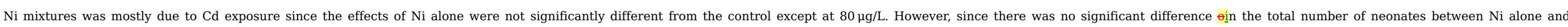
its corresponding $\mathrm{Cd}$

Ni mixture at higher Ni concentrations, the reproductive effects observed in the $\mathrm{Cd}$

Ni mixtures containing 100, 120, 140, and $160 \mu \mathrm{\mu g} / \mathrm{L}$ Ni were mostly due to Ni exposure or both Ni and Cd exposure (Fig. 2II)

$$
\text { Dissimilarly, none of the } \mathrm{Cd}
$$

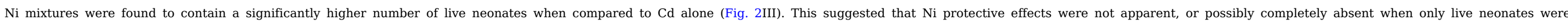
considered in analysis. In addition, at 20 and $40 \mu \mathrm{g} / \mathrm{L}$ Ni alone, the total number of live neonates did not significantly differ from the control (Fig. 2III). The effect in the total number of live neonate observed in those Cd

Ni mixtures was mostly due to Cd exposure. Similarly, the results obtained for the overall reproductive rate (Fig. 3I), and the live neonate reproductive rate (Fig. 3II) showed that none of the Cd

Ni mixtures hat a

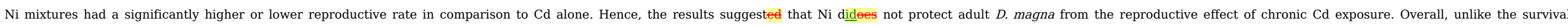
results, a less-than-additive effect was not observed on the reproductive endpoint of $D$. magna even when Ni concentration was sufficient, except when both dead and live neonates are collectively considered (Fig. 2II). 


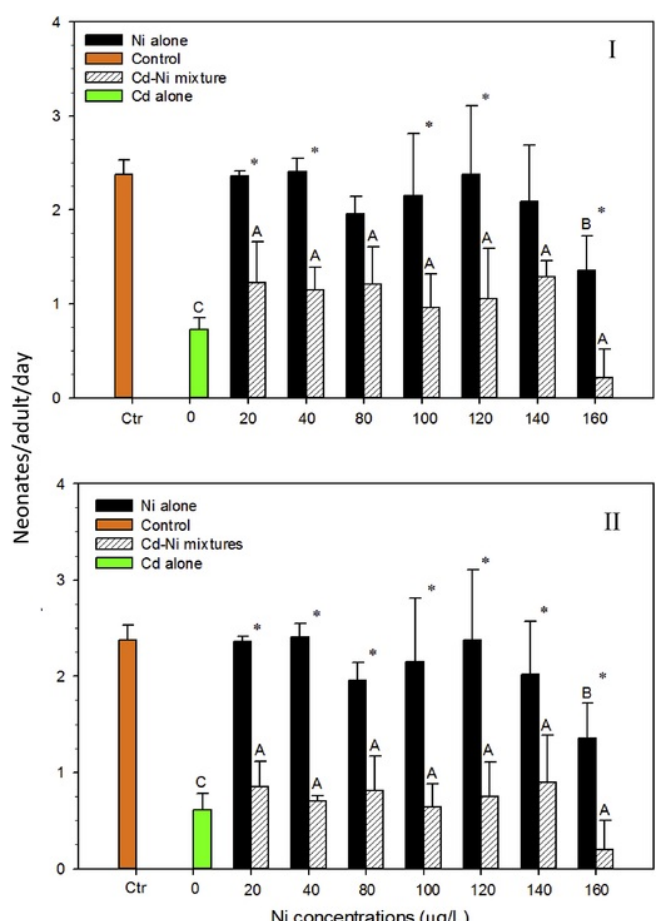

Fig. 3 Overall dead and live (I) and live (II) neonate reproductive rates of $D$. magna when exposed to $\mathrm{Cd}$ alone, Ni alone, and Cd

Ni mixtures containing constant Cd concentration of $1.5 \mu \mathrm{g} / \mathrm{L}$ and varied Ni concentrations. A: significant differences between control and Cd

Ni mixtures $(p<0.01)$. B: significant differences between control and Ni alone $(p<0.05)$. C: significant difference between control and Cd alone $(p<0.001)$. *: significant differences between a Ni alone and its corresponding Cd

Ni mixture $(p<0.05)$. Error bars represent standard deviations.

("Cd-Ni" in the figure title should be one word and in the same line) alt-text: Fig. 3

For the reproductive rate, there was no statistically significant difference in the overall and live neonate reproductive rates between $\mathrm{Cd}$ alone and the $\mathrm{Cd}$

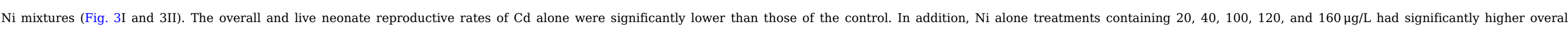
reproductive rates than their corresponding $\mathrm{Cd}$

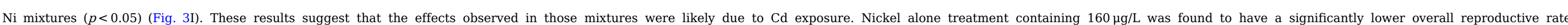

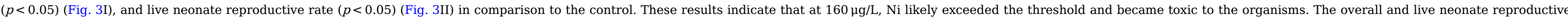
rates in the $\mathrm{Cd}$

$\mathrm{Ni}$ mixture containing $160 \mu \mathrm{g} / \mathrm{L}$ Ni were significantly lower than those in the $160 \mu \mathrm{g} / \mathrm{L} \mathrm{Ni}$ alone treatment, suggesting the effects in this mixture were due to both Cd and Ni exposure

\subsubsection{Total dead neonates and undeveloped embryos}

The percentage of dead neonates was significantly higher in the $\mathrm{Cd}$

Ni mixtures containing 20, 40, 80, 100, and $120 \mu \mathrm{g} / \mathrm{L} \mathrm{Ni}$ in comparison to the Cd alone treatment $(p<0.05)$ (Fig. 4I). This difference was not observed for other Cd

Ni mixtures (Fig. $4 \mathrm{I}$ ). These results revealed that $D$. magna in the $\mathrm{Cd}$ 
Ni mixtures (Fig. 4I) as evident by the higher percentage of dead neonates (Fig. 4I).

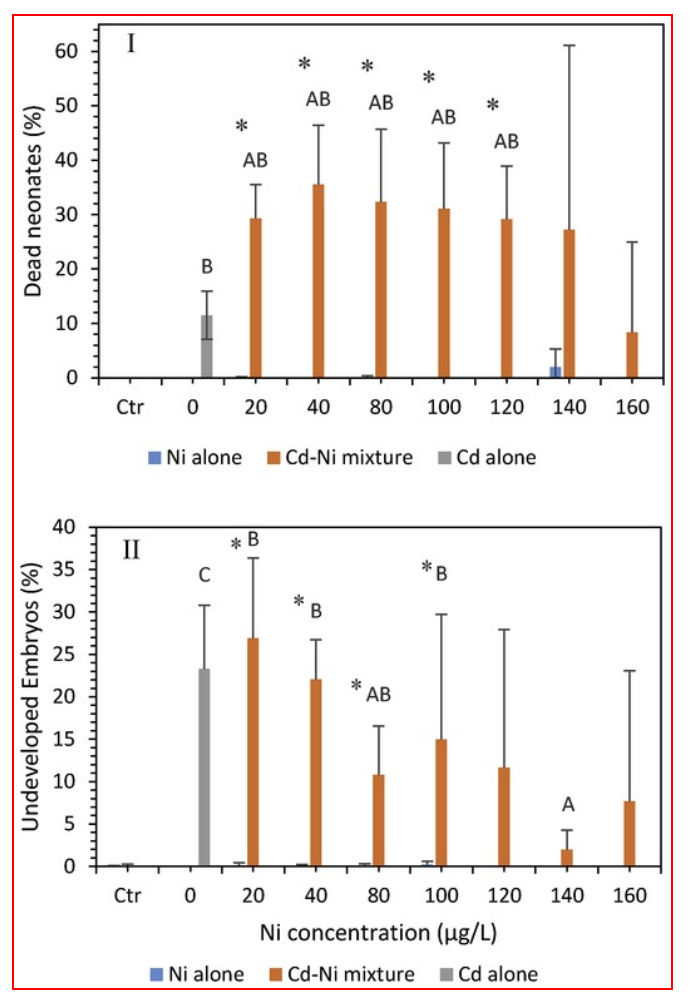

Fig. 4 Total dead neonates reproduced (I) and undeveloped embryos observed (II) over 21-d of exposure to Cd alone, Ni alone, and Cd

Ni mixtures containing constant Cd concentration of $1.5 \mathrm{\mu g} / \mathrm{L}$ and varied Ni concentrations. A: significant differences between Cd alone and Cd

Ni mixtures $(p<0.05)$. B: significant differences between control and Cd

Ni mixtures $(p<0.001)$. C: significant difference between control and Cd alone $(p<0.001)$. *: significant differences between a Ni alone and its corresponding Cd

Ni mixtures $(p<0.001)$. Error bars represent standard deviations.

\section{("Cd-Ni" in the figure titles should be one word and in the same line) alt-text: Fig. 4}

None of the Ni alone treatments had a significantly higher percentage of dead neonates in comparison to the control (Fig. 4I). However, Cd alone and Cd

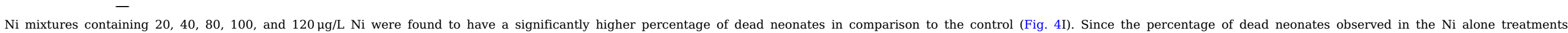
containing 20,40,80,100, and $120 \mu \mathrm{g} / \mathrm{L}$ were significantly lower than their corresponding Cd

Ni mixtures $(p<0.001)$ (Fig. 4I), the effects observed in those Cd

Ni mixtures were likely due to $\mathrm{Cd}$ exposure. However, the effects observed in the $\mathrm{Cd}$

Ni mixtures containing $\geq 140 \mu \mathrm{g} / \mathrm{L}$ Ni were mostly due to Cd exposure or both Ni and Cd exposure. 
Only the $\mathrm{Cd}$

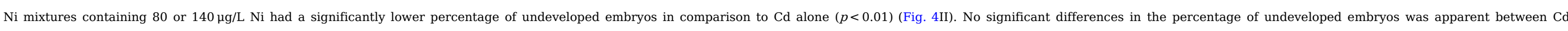
alone and the other $\mathrm{Cd}$

Ni mixtures. These results indicate that the $\mathrm{Cd}$

Ni mixtures with 20 or $40 \mu \mathrm{g} / \mathrm{L}$ Ni did not provide protective effects to $D$. magna embryos (Fig. 4II).

The percentage of undeveloped embryos observed in all Ni alone treatments were not significantly different from the control (Fig. 4II). However, the percentage of undeveloped embryos observed in Cd alone, and the Cd

Ni mixtures containing 20,40,80, and $100 \mu \mathrm{g} / \mathrm{L}$ Ni were significantly higher in comparison to the control $(p<0.001)$ (Fig. 4II). These results indicate that the embryotoxicity observed in those Cd

Ni mixtures was likely due to Cd exposure.

The results from morphological examination revealed developmental obstructions and morphological alterations in embryos exposed to $\mathrm{Cd}$

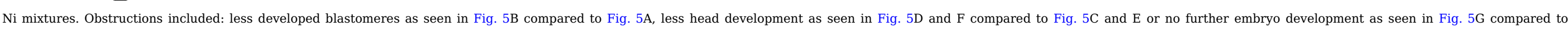
Fig. 5H. The effects could be either halted mitotic cell division (cleavage) or disrupted cellular arrangement and organization which likely prevented the development of an embryo. 

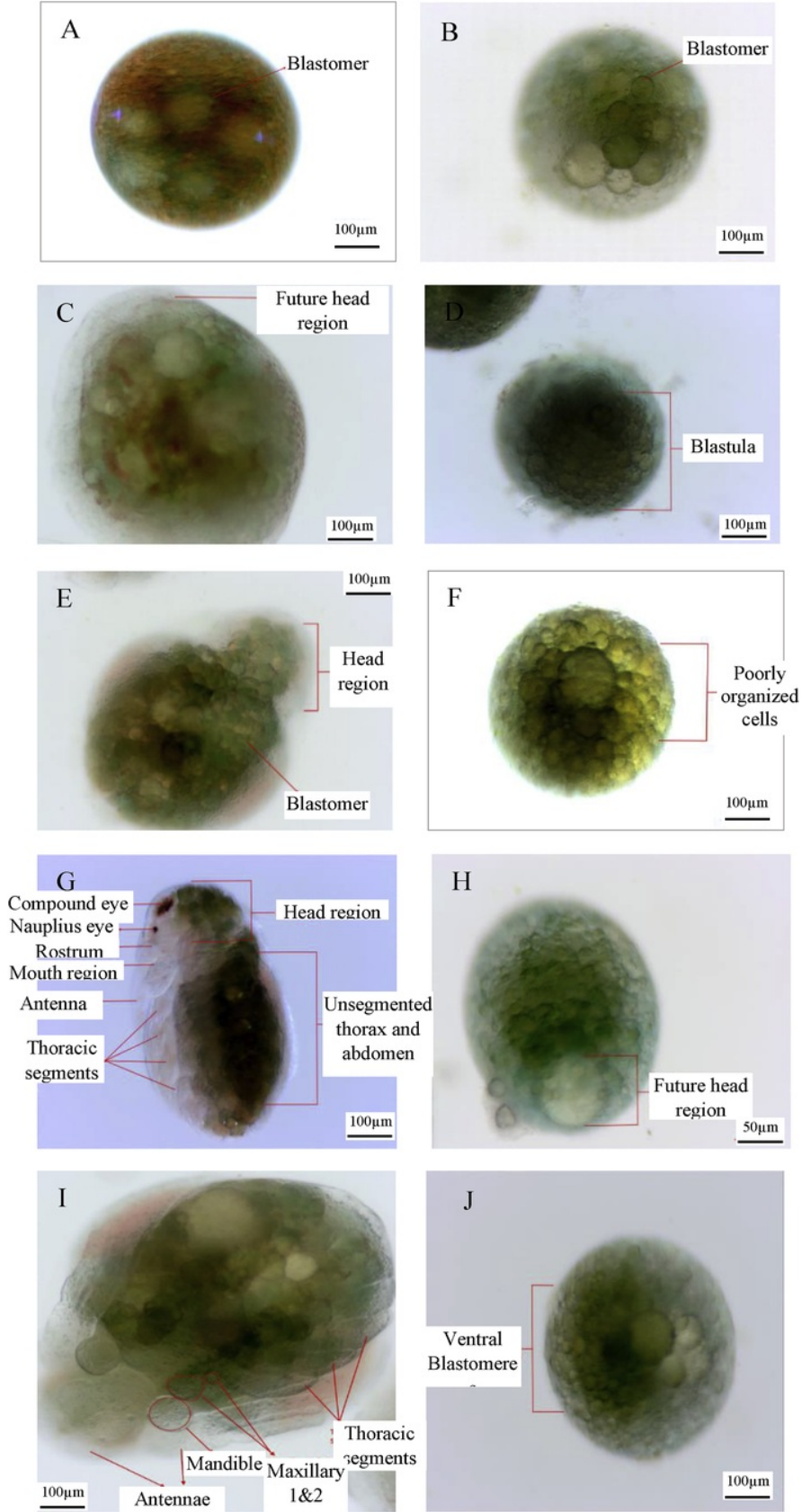

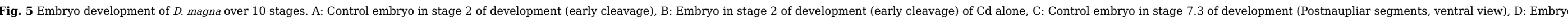
in stage 2 of development (late cleavage) for $\mathrm{Cd}$

Ni mixture with $140 \mathrm{\mu g} / \mathrm{L} \mathrm{Ni}$, E: Control embryo in stage 9 of development (appearance of compound and nauplius eye, dorsal view), F: Embryo in stage 3 of development (gastrulation) for Cd 
Ni mixture with $120 \mathrm{\mu g} / \mathrm{L} \mathrm{Ni}$, G: Control embryo in stage 9 of development (lateral view), H: Embryo in stage 5 of development (head formation, anterodorsal view) for Cd

Ni mixture with $20 \mu \mathrm{g} / \mathrm{L}$ Ni. I: Control embryo in stage 10 of development (hook-shaped abdomen, ventral view), J: Embryo in stage 3 of development (gastrulation, anteroventral view) for Cd

Ni mixture with $40 \mathrm{\mu g} / \mathrm{L}$ Ni.

\section{alt-text: Fig. 5 ("Cd-Ni" in the figure titles should be one word and in the same line)}

\subsection{Body weight}

The average dry weights of the surviving $D$. magna in $\mathrm{Cd}$

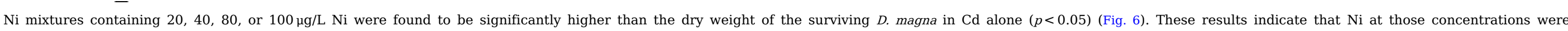
sufficient to protect $D$. magna from the growth effect of Cd. At higher Ni concentrations, the dry weights of the surviving D. magna in Cd alone and Cd

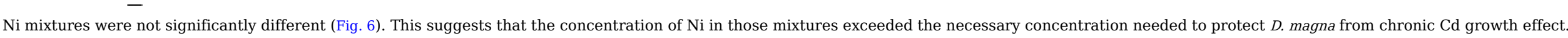

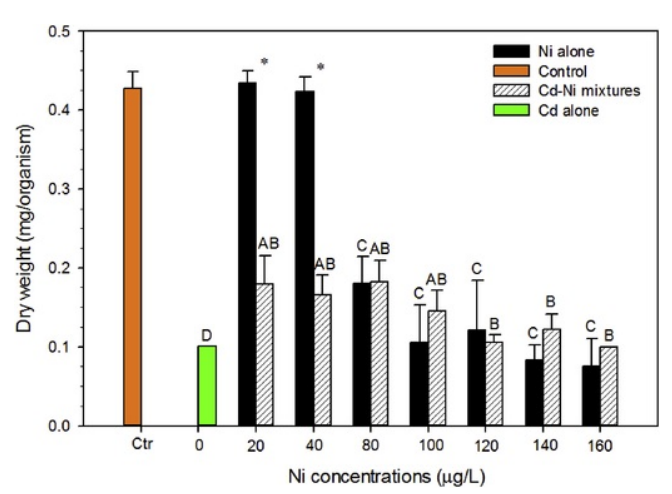

Fig. 6 Dry weight of surviving adults at test termination. A: significant differences between $\mathrm{Cd}$ alone and $\mathrm{Cd}$

Ni mixtures $(p<0.05)$. B: significant differences between control and Cd

Ni mixtures $(p<0.001)$. C: significant differences between control and Ni alone $(p<0.001)$. D: significant difference between control and Cd alone $(p<0.001)$. *significant differences between a Ni alone and its corresponding Cd

Ni mixture $(p<0.001)$. Error bars represent standard deviations.

("Cd-Ni" in the figure titles should be one word and in the same line) alt-text: Fig. 6

The dry weights of the surviving $D$. magna in the Ni alone treatments containing 20 and $40 \mu \mathrm{g} / \mathrm{L}$ Ni were significantly higher in comparison to their corresponding Cd

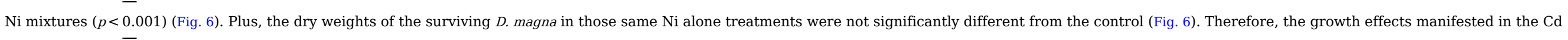

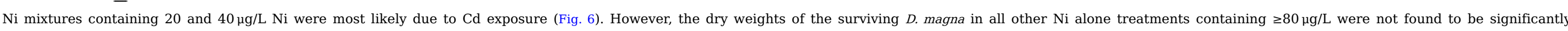
higher than their corresponding Cd

Ni mixture (Fig. 6), but they were significantly lower than the control ( $p<0.001)$ (Fig. 6). These results suggest that the growth effects observed in Cd

Ni mixtures containing $\geq 80 \mu \mathrm{g} / \mathrm{L}$ was mostly due to Ni exposure.

\subsection{Metal accumulation effects}

The measured $\mathrm{Cd}$ concentrations in the tissues of the surviving daphnids exposed to $\mathrm{Cd}$ alone and to $\mathrm{Cd}$

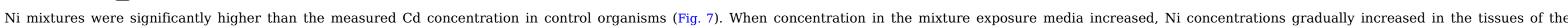




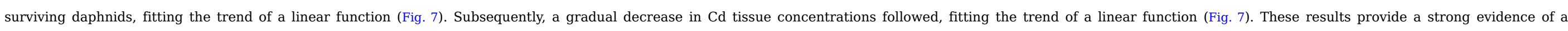
competitive accumulation of $\mathrm{Ni}$ and $\mathrm{Cd}$.

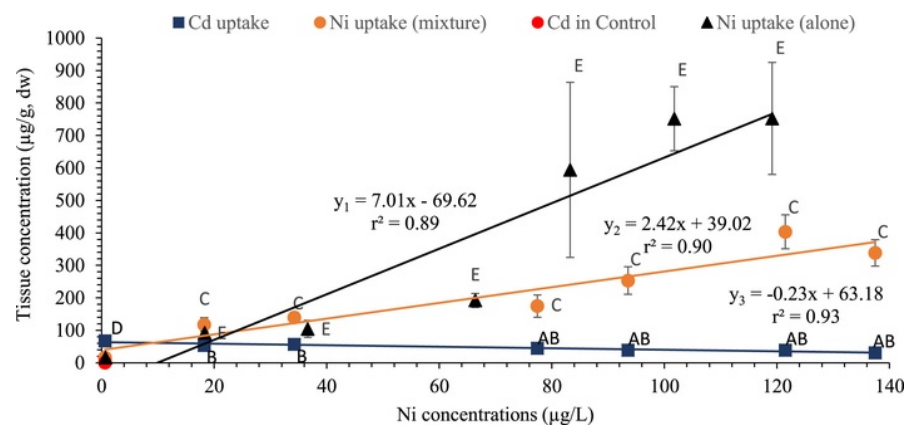

Fig. 7 Relationship between water metal concentration and body concentration of surviving daphnids exposed to $\mathrm{Ni}$ alone and $\mathrm{Cd}$

Ni mixture over 21 days. A: significant differences between $\mathrm{Cd}$ alone and $\mathrm{Cd}$

$-$

Ni mixtures $(p<0.05)$. B: significant differences between control and Cd

$-$

Ni mixtures $(p<0.05)$. C: significant differences between control and Cd

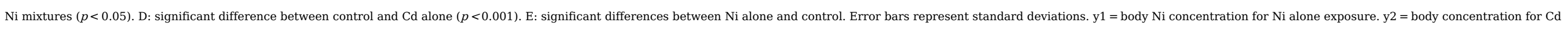

Ni mixture exposure. $\mathrm{y} 3=$ body $\mathrm{Cd}$ concentration for $\mathrm{Cd}$

Ni mixture exposure.

\section{("Cd-Ni" in the figure titles should be one word and in the same line) alt-text: Fig. 7}

The results obtained from tissue analysis of the surviving daphnids in the $\mathrm{Cd}$

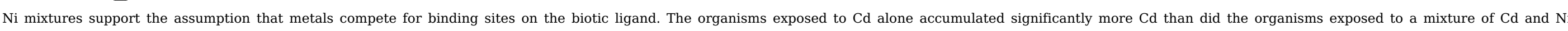
$(p<0.05)$, except the mixtures containing 20 and $40 \mu \mathrm{g} / \mathrm{L} \mathrm{Ni}$ (Fig. 7). Only the daphnids in the Cd

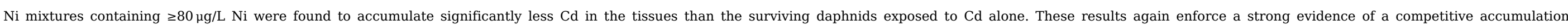
effect which results in a less-than-additive effect in $\mathrm{Cd}$

$\mathrm{Ni}$ mixtures at Ni concentrations less than $80 \mu \mathrm{g} / \mathrm{L}$.

\section{Discussion}

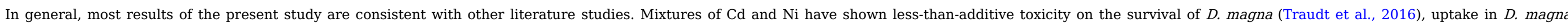

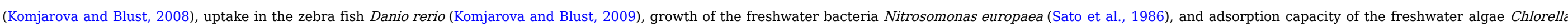
vulgaris (Awasthi and Rai, 2004). However, at high Ni concentrations (i.e., 100-160 $\mathrm{gg} / \mathrm{L}$ ) in a mixture with Cd, Ni became toxic to the organisms. The less-than-additive or joint toxic effect in the Cd

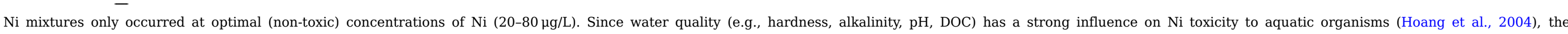

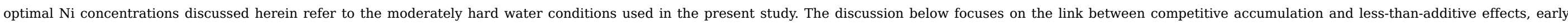
reproduction and possible detoxification mechanisms, and effect on embryo development.

\subsection{Less-than-additive effect and competitive metal accumulation}

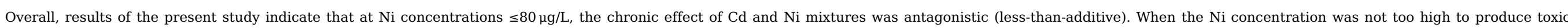




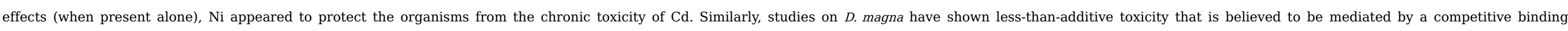

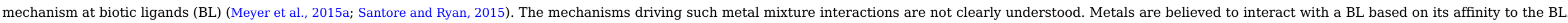
A metal with the strongest affinity for a BL will occupy more binding sites and be accumulated more in an organism than metals with less affinity.

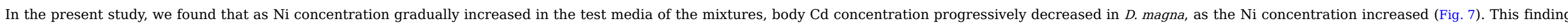
supports the competitive binding mechanism of metals at the BL and agrees with the results published by Komjarova and Blust (2008). Our earlier chronic exposure study with Cd

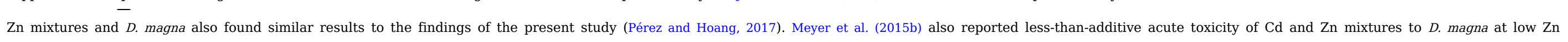
concentrations but Zn appeared to contribute to the toxicity at high Zn concentrations.

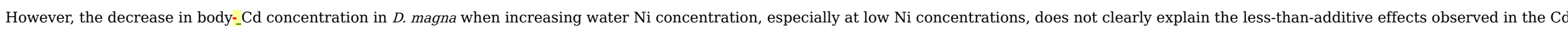
or example, D. magna exposed to $\mathrm{Cd}$ Ni mixtures. For example, D. magna exposed to Cd

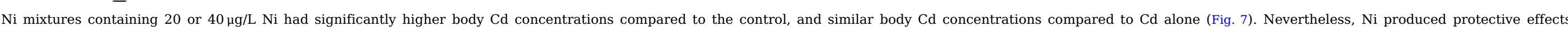

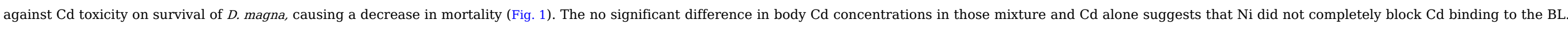

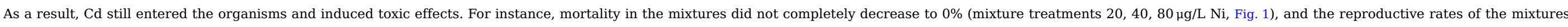

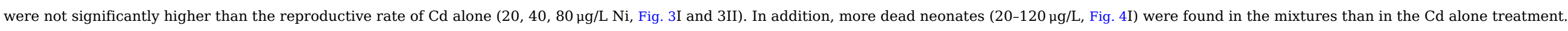

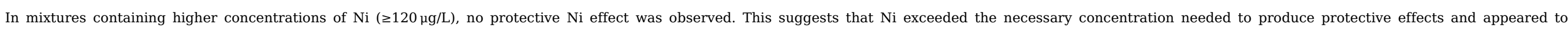
contribute to the toxicity.

\subsection{Early reproduction, food consumption, and possible detoxification mechanism}

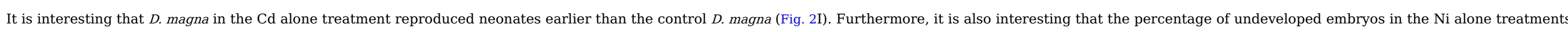

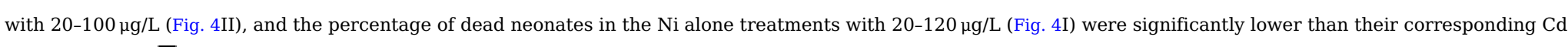

Ni mixtures (Fig. 4 I and $4 \mathrm{II})$. Our earlier study on $\mathrm{Cd}$

Zn mixtures and $D$. magna found similar results (Pérez and Hoang, 2017).

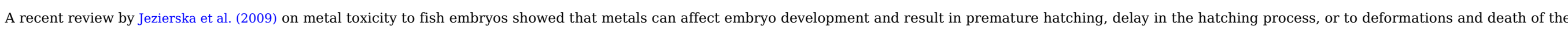

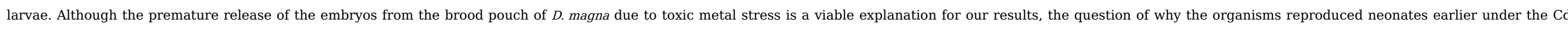

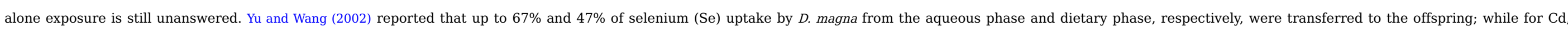

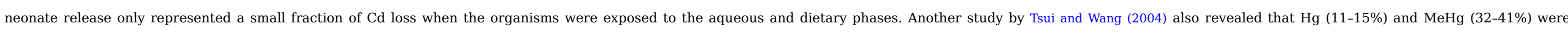

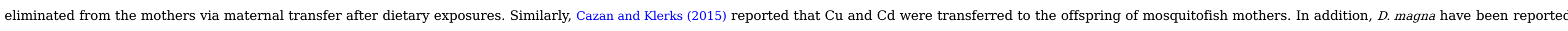

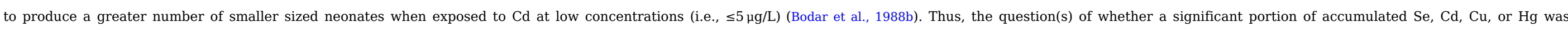

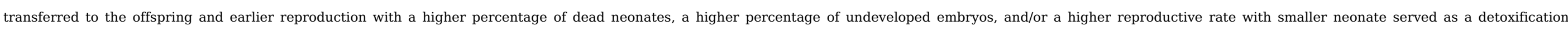
mechanism are still unanswered. Further studies are needed to answer this question.

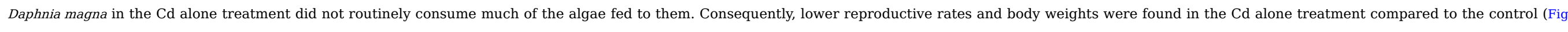

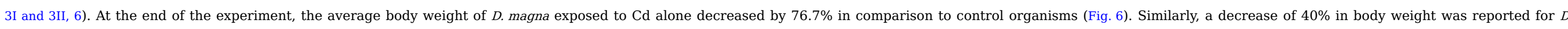

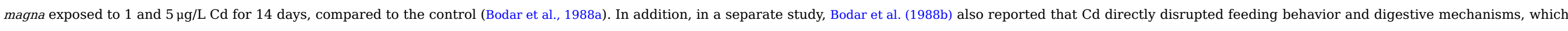

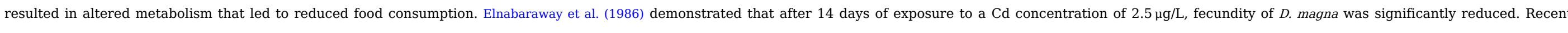

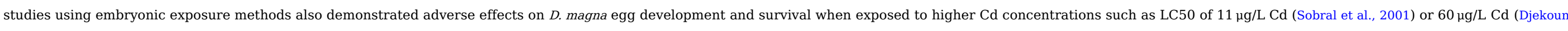

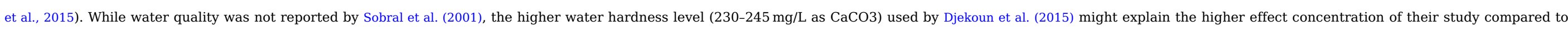




\subsection{Effects on embryo development}

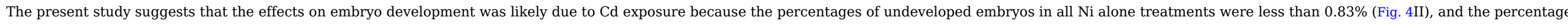
of aborted embryos in the Cd

Ni mixtures containing 20-100 $\mu$ g/L Ni were significantly higher than their corresponding Ni alone pairs (Fig. 4II).

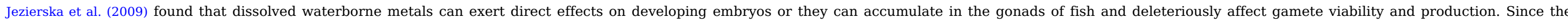

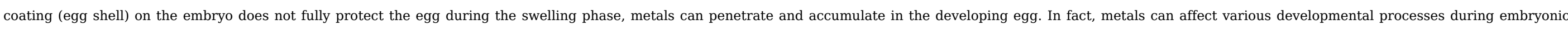

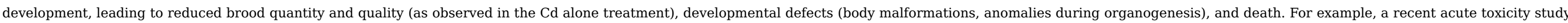

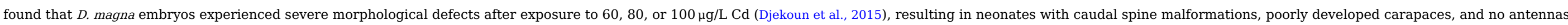

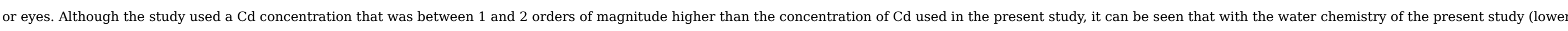
hardness than the hardness used in the study above, $245 \mathrm{mg} / \mathrm{L}$ as $\left.\mathrm{CaCO}_{3}\right), 1.5 \mu \mathrm{g} / \mathrm{L} \mathrm{Cd}$ with chronic exposure is sufficient to cause embryonic deformities.

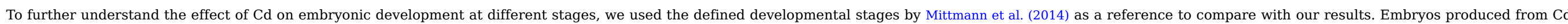
alone and the $\mathrm{Cd}$

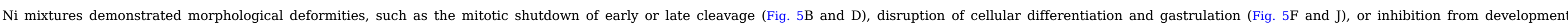
beyond stage 5 (Fig. 5H); unlike control embryos, which displayed normal cleavage and a higher degree of faithful cellular arrangement, differentiation, and organization (Fig. 5A, C, 5E, 5G, 5I).

Our results further showed that embryos exposed to Cd alone only underwent early cleavage (8 cell stage to morula) (Fig. 5B), while embryos exposed to the Cd

Ni mixtures either progressed to a blastula (Fig. 5D), underwent gastrulation (Fig. 5F and J), or developed to stage 5

and idly arranged into a splotch of cells (Fig. 5F). This indicated some degree of protective Ni effects against Cd toxicity.

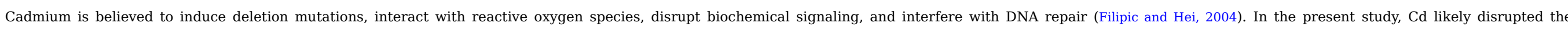

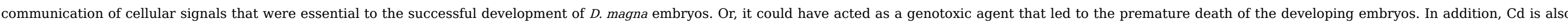

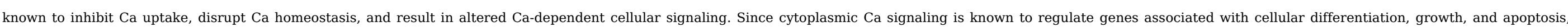
disruption of those biochemical pathways would have led to deleterious effects such as DNA damage, malignant cellular growth, and transcriptional abnormalities (Kasprzak and Salnikow, 2007).

\section{Conclusions and suggestions}

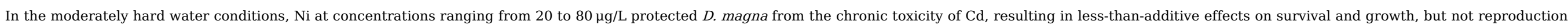
Therefore, Cd

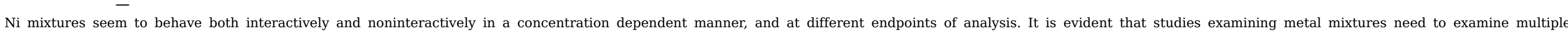

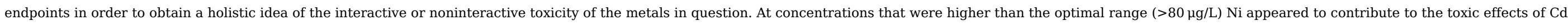

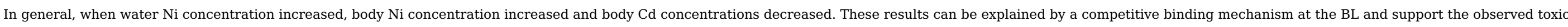
effects.

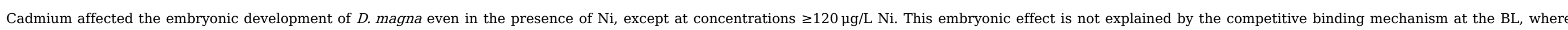

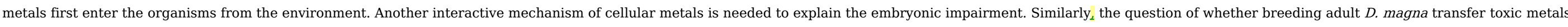

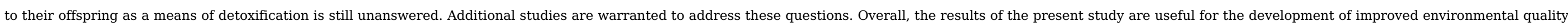
guidelines for metal mixtures. 


\section{Acknowledgement}

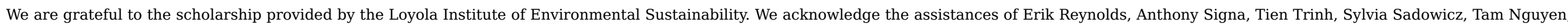

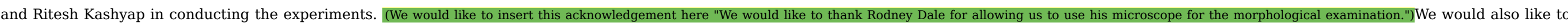
thank Martin Berg for his assistance with data analysis and Stephen Mitten for contributing valuable comments and suggestions.

\section{Appendix A. Supplementary data}

Supplementary data related to this article can be found at https://doi.org/10.1016/j.chemosphere.2018.06.063.

\section{References}

Agency for Toxic Substances and Disease Registry (ATSDR), Toxicological Profile for Nickel, (Update)2005, Public Health Service, US Department of Health and Human Services; Atlanta, GA, USA.

Agency for Toxic Substances and Disease Registry (ATSDR), Toxicological Profile for Cadmium (Update), 2012, Public Health Service, US Department of Health and Human Services; Atlanta, GA, USA.

ASTM, Standard Guide for Conducting Daphnia Magna Life-cycle Toxicity Tests, E1193-97, 2012, ASTM International; West Conshohocken, PA, USA.

Awasthi M. and Rai L.C., Adsorption of nickel, zinc, and cadmium by immobilized green algae and cyanobacteria: a comparative study, Ann. Microbiol. 54 (3), 2004, 257-267.

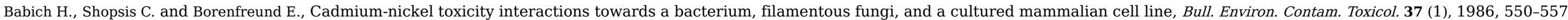

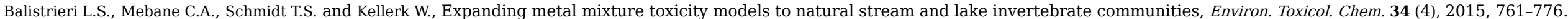

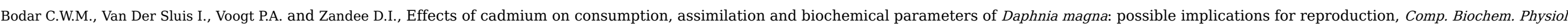

90C (2), 1988a, 341-346.

Bodar C.W.M., Van Leeuwen C.J., Voogt P.A. and Zandee D.I., Effect of Cadmium on the reproduction strategy of Daphnia magna, Aquat. Toxicol. 12 (4), $1988 b, 301-310$.

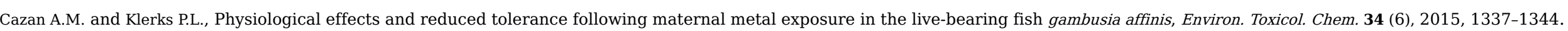

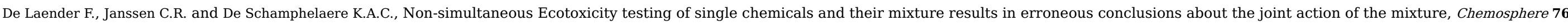
$2009,428-432$.

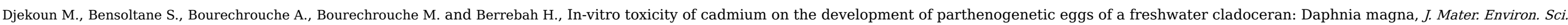
(4), 2015, 957-962.

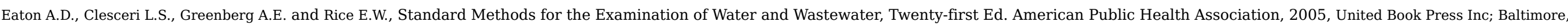

Maryland, USA.

Eisler R., Nickel Hazards to Fish, Wildlife, and Invertebrates: a Synoptic Review, 1998, US Geological Survey, Biological Resources Division, Biological Science Report.

Elnabaraway M.T., Welter A.N. and Robideau R.R., Relative sensitivity to three daphnid species to selected organic and inorganic chemicals, Environ. Toxicol. Chem. 5 (4), 1986, 393-398.

ENVIRODAT, National Environmental Quality Data Bank Codes Dictionary, 1992, Inland Waters Directorate, Environment Canada; Ottawa, Water Quality Branch.

Filipic M. and Hei T.K., Mutagenicity of cadmium in mammalian cells: implication of oxidative DNA damage, Mutat. Res. Fund Mol. M 546 (1-2), 2004, 81-91.

Hoang T.C., Tomasso J.R. and Klaine S.J., Influence of water quality and age on nickel toxicity to fathead minnows (Pimephales promelas), Environ. Toxicol. Chem. 23, 2004, 86-92.

Jezierska B., Ługowska K. and Witeska M., The effects of heavy metal on the embryonic development of fish (a review), Fish Physiol. Biochem. 35 (4), 2009 , 625-640. 


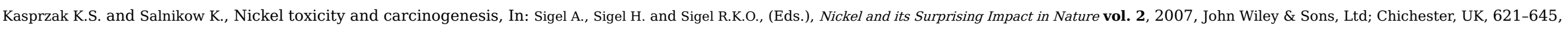

https://doi.org/10.1002/9780470028131.ch17.

Komjarova I. and Blust R., Multi-metal interactions between Cd, Cu, Ni, Pb, and Zn in water flea Daphnia magna, a stable isotope experiment, Aquat. Toxicol. 90, 2008, 138-144.

Komjarova I. and Blust R., Multi-metal interactions between Cd, Cu, Pb, and Zn uptake from water in the Zebrafish Danio rerio, Environ. Sci. Technol. 43, 2009, 7225-7229.

Meyer S.J., Farley J.K. and Garman R.E., Metal mixtures modeling evaluation project: 1. Background, Environ. Toxicol. Chem. 34 (4), $2015 a, 726-740$.

Meyer S.J., Ranville F.J., Pontasch M., Gorsuch W.J. and Adams J.W., Acute toxicity of binary and ternary mixtures of Cd, Cu and Zn to Daphnia magna, Environ. Toxicol. Chem. 34 (4), 2015b, 799-808.

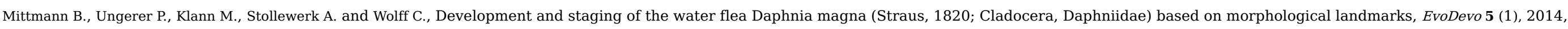

$1-20$.

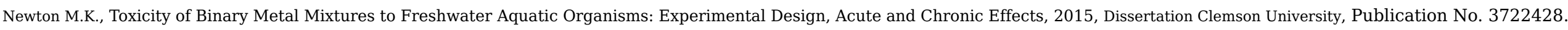

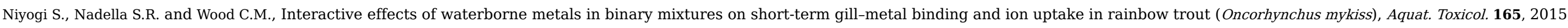
$109-119$.

Norwood W.P., Borgmann U., Dixon D.G. and Wallace A., Effects of metal mixtures on aquatic biota: a review of observations and methods, Hum. Ecol. Risk Assess. 9, 2003 , 795-811.

Pérez E. and Hoang T.C., Chronic toxicity of binary-metal mixtures of cadmium and zinc to Daphnia magna, Environ. Toxicol. Chem. 36 (10), 2017, 2739-2749.

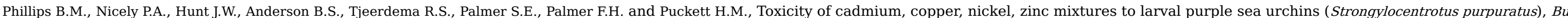
Environ. Contam. Toxicol. 70, 2003, 592-599.

Santore R.D. and Ryan A.C., Development and application of a multimetal multibiotic ligand model, Environ. Toxicol. Chem. 34, 2015, 777-787.

Sato C., Schnoor J.L. and McDonald D.B., Characterization of effects of copper, cadmium, and nickel on the growth of Nitrosomonas europaea, Environ. Toxicol. Chem. 5, 1986, 403-416.

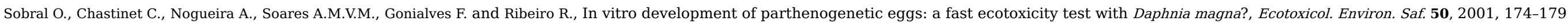

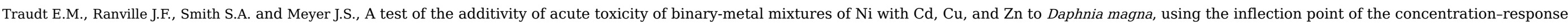

curves, Environ. Toxicol. Chem. 35, 2016, 1843-1851.

Tsui M.T.K. and Wang W.-X., Uptake and elimination routes of inorganic mercury and methylmercury in Daphnia magna, Environ. Sci. Technol. 38.3, 2004, 808-816.

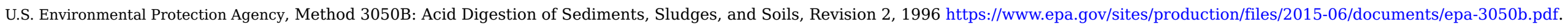

U.S. Environmental Protection Agency, Update of Ambient Water Quality Criteria for Cadmium, EPA-822-r-01-001. Final Report2001, Office of Water; Washington, DC.

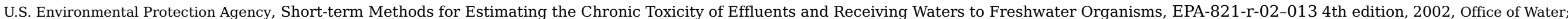

Washington, DC.

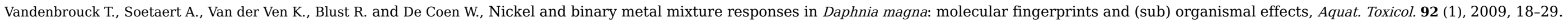
Vijver M.G., Elliot E.G., Peijnenburg W.J.G.M. and De Snoo G.R., Response prediction for organisms water-exposed to metal mixtures: a meta-analysis, Environ. Toxicol. Chem. 30, 2011 , $1482-1487$.

Yu R.Q. and Wang W.X., Trace metal assimilation and release budget in Daphnia magna, Limnol. Oceanogr. 47, 2002, 495-504.

\section{Appendix A. Supplementary data}




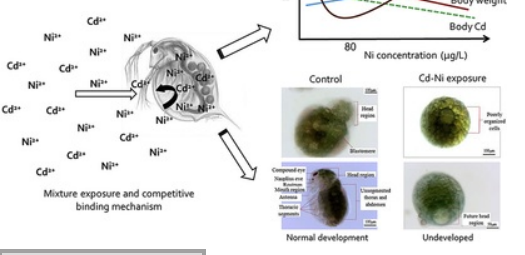

alt-text: Image 1

\section{Highlights}

- At low concentrations, Ni protected Daphnia magna from Cd toxicity

- At high concentrations, $\mathrm{Ni}$ contributed to the toxicity of $\mathrm{Cd}$.

- Protective effect of Ni was not clearly observed for reproductive endpoints.

- Cadmium affected embryotic development of Daphnia magna but Ni did not.

- Competitive metal uptake between $\mathrm{Ni}$ and Cd by Daphnia magna was observed.

\section{Queries and Answers}

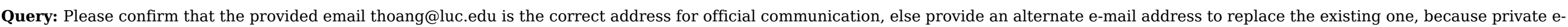
mail addresses should not be used in articles as the address for communication.

Answer: correct

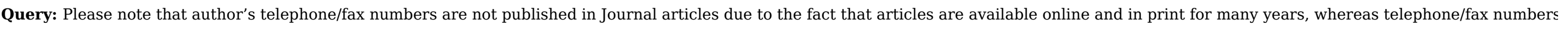
are changeable and therefore not reliable in the long term.

Answer: agree

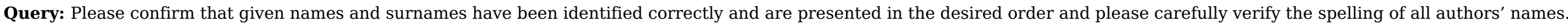

Answer: correct 


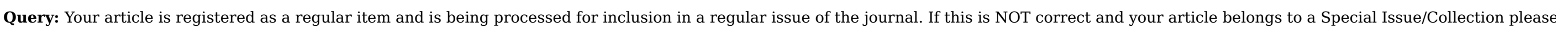
contact p.das@elsevier.com immediately prior to returning your corrections.

Answer: This paper is for a regular issue 